\title{
Longitudinal associations of parental and peer influences with physical activity during adolescence: findings from the COMPASS study
}

\section{E. Y. Lau, PhD (1); G. Faulkner, PhD (1); W. Qian, MS (2); S. T. Leatherdale, PhD (2)}

This article has been peer reviewed.

\begin{abstract}
Introduction: To examine temporal variations in parental and peer influences on adolescent physical activity (PA) and whether these variations predicted changes in PA.

Methods: We analyzed data from Years 1, 2 and 3 of the COMPASS study. Participants were 22909 students in Grades 9 to 12 (mean age [years] $=15.42 \pm 1.12$, 46\% boys, $85 \%$ White), who had completed the following survey items on 2 or more consecutive occasions: age, sex, grade, race/ethnicity, moderate-to-vigorous physical activity (MVPA), parental encouragement and parental instrumental support for PA, and number of active peers. We used a linear-mixed model to investigate longitudinal effects of parental and peer influences on changes in square-root transformed average MVPA. We used a generalized-estimatingequations (GEE) model to investigate compliance with Canadian PA guidelines for youth. These models included parental encouragement, instrumental support and number of active peers as time-varying predictors, adjusting for sociodemographic factors and grade as covariates, and accounting for the clustering within children and schools.
\end{abstract}

Results: We found that adolescents perceived significantly less parental encouragement and instrumental support and reported fewer active peers as they got older. In addition, the adjusted models suggest that, for a one-unit increase in the score of parental encouragement, parental instrumental support and number of active peers, average MVPA significantly increased by 0.22 units, 0.23 units and 0.16 units, respectively. For the same one-unit increase, adjusted odds of an adolescent complying with the PA guidelines increased by $9 \%$, $4 \%$ and $6 \%$, respectively.

Conclusion: Promoting parental support and facilitating the formation and maintenance of a physically active friendship network may play an important role in attenuating declines in PA during adolescence.

Keywords: parental encouragement, parental instrumental support, active peers, physical activity

\section{Introduction}

Regular physical activity (PA) has been shown to have positive effects on health in children and adolescents, including bone health, mental health, weight management, lipid profile and insulin sensitivity. ${ }^{1,2}$ Despite the well-recognized benefits of PA, a small proportion of children achieve the goal set out in the national PA guidelines for children and adolescents of accumulating at least 60 minutes of moderate-to-vigorous physical activity (MVPA) per day. ${ }^{3-5}$ Compliance is even lower among adolescents. ${ }^{3-5}$ Because PA habits during adolescence tend to track into adulthood, ${ }^{6}$ which in turn influences the risk of developing chronic diseases later in life, ${ }^{2}$ promoting a more physically active lifestyle in this age group is critical.
Highlights

- This longitudinal study advances current knowledge by demonstrating declining trends in parental encouragement, instrumental support and the number of active peers during adolescence.

- Increases in the number of active peers and in parental support predicted increases in PA.

- Family- and peer-based interventions require further development and evaluation.

In order to promote a more physically active lifestyle, it is important that the correlates of PA in adolescents be identified to inform the development of intervention strategies. ${ }^{7} \mathrm{PA}$ is a complex behaviour because it is influenced by correlates operating at individual, social, environmental and community levels. ${ }^{8}$ Although there is an extensive body of research related to individual-level correlates of PA (e.g. selfefficacy and attitude), relatively less research has been focussed on social correlates, including parental and peer influences. $^{9}$ For example, social cognitive theory suggests that social support is likely to be a determinant of youth PA. ${ }^{10}$

Cross-sectional evidence consistently shows that adolescents are more likely to participate in PA if they perceive more support for PA from parents and friends. ${ }^{11,12}$ However, there are only a few studies that examine these associations using longitudinal study designs. ${ }^{13-21}$ Among the few available longitudinal studies, parental and peer influences 
measured at baseline were found to be positively associated with prospective PA levels in adolescents. Additionally, there is limited evidence indicating that variations in parental and peer influences throughout adolescence also significantly predicted changes in adolescent PA over time. Thus far, only three studies have demonstrated that parental influences tend to decline as adolescents age, and that reductions in these influences appear to be associated with steeper decline in PA during adolescence. ${ }^{22-24}$ More studies focussing on prospective changes in parental and peer influences and their effects on changes in adolescent PA are needed to strengthen the evidence base.

One of the methodological problems in this line of research is inconsistency in the conceptualization of parental and peer influences. ${ }^{25}$ Researchers agree that parents can influence PA of their adolescent children in several ways, including role modelling, encouragement, instrumental support (e.g. transportation and equipment), positive communication and coparticipation. ${ }^{25}$ However, some studies summarize all of these means of influence into a composite score to reflect parental influences on PA, ${ }^{18,24,26}$ while others quantify them separately. ${ }^{19,21,22}$ Researchers have noted that not all aspects of parental influence are equally influential on adolescent PA. ${ }^{25}$ Evidence from systematic reviews has shown that parental encouragement and instrumental support (e.g. transportation) were more strongly related to adolescent PA. However, these findings were primarily based on cross-sectional studies. Therefore, longitudinal studies are needed to examine the temporal associations of parental encouragement and instrumental support with adolescent PA. ${ }^{27,28}$

In terms of peer influences, previous studies suggest that a youth's friendship network could have a powerful influence on their PA levels by providing various forms of support, such as positive communication, co-participation and role modelling. ${ }^{12,29}$ However, a prerequisite is the presence of friends who are physically active. It is, therefore, important to understand the influences of the number of physically active peers on PA participation. To date, no longitudinal study has examined such associations.
In Canada, the effects of parental and peer support on physical activity have not been measured consistently. ${ }^{30}$ From 2005 to 2014, Active Healthy Kids Canada released the Report Card on Physical Activity for Children and Youth, and ParticipACTION has released it since 2015. ${ }^{31}$ Each annual Report Card assigns letter grades to different influences of PA, including Settings and Sources of Influence (with subcategories of Family and Peers, School, and Community and Environment). Over the years, however, the Report Card has not provided consistent, gradable data for peer and parental influence. The indicator for peer influence was not graded at all. The grade for parental influence was informed by family physical activity data, but this is not a direct measure of parental support, which may include components such as encouragement and instrumental support.

The 2015 Report Card called for prospective research examining whether changes in parental and peer support explain changes in physical activity over time. In order to address this call, the present study aimed to examine 1) variations in parental encouragement for PA, parental instrumental support for PA, and the number of active peers across Grades 9 to 12; and 2) whether these variations predicted changes in PA from Grades 9 to 12 in a sample of Canadian adolescents.

\section{Methods}

\section{Sample and population}

The COMPASS study is an ongoing prospective cohort study that began in 2012/2013. The study was designed to examine longitudinal associations between school policies and programs with youth health behaviours (i.e. physical activity, healthy eating, smoking, and alcohol and marijuana use). ${ }^{32}$ The study collects hierarchical longitudinal data from a convenience sample of secondary schools and the Grades 9 to 12 students attending these schools. This study analyzed data for three time points: Years 1 (2012/2013), 2 (2013/2014) and 3 (2014/2015). Extensive details on the COMPASS study, including sampling, data collection and linkage process, are available online (www.compass .uwaterloo.ca).

The study initially recruited 43 Ontario schools in Year 1; 79 Ontario schools (including all Year 1 schools) and 10 Alberta schools in Year 2; and 78 Ontario schools (one Year 2 school left, but two new schools joined the study) and 9 Alberta schools (one left the study) in Year 3. All Grades 9 to 12 students attending these schools were invited to participate in the study and reported data by completing the COMPASS student questionnaire (Cq) annually. The COMPASS study was approved by the Human Research Ethics Board at the University of Waterloo.

In Year 1, the study enrolled 30147 students in Grades 9 to 12, and 24173 of them $(80.2 \%)$ completed the Cq. In Year 2, 57229 students in Grades 9 to 12 were enrolled, and 45298 of them (79.1\%) completed the Cq. In Year 3, 53846 students in Grades 9 to 12 were enrolled, and 42355 of them $(78.7 \%)$ completed the Cq. Missing respondents resulted primarily from scheduled spares or absenteeism at the time of the $\mathrm{Cq}$, and minimally from student or parent refusal (1\%). Selfgenerated identification codes were used to link data sets for three years and create longitudinal data. In our study, we considered participants who had completed the $\mathrm{Cq}$ for at least 2 consecutive years, which resulted in a longitudinal sample of 26081 participants. Of this group, we excluded 3172 participants who were missing data on PA or parental and peer influences variables, or had inconsistent records on sex or ethnicity across years. This resulted in the final longitudinal sample of 22909 participants.

\section{Measures}

\section{Dependent variable: physical activity}

At each time point, participants were asked to respond to two items on the Cq about how many minutes of vigorous and moderate PA they had done on each of the last 7 days. Vigorous PA was defined as activities that "increase your heart rate and make you breathe hard and sweat," such as jogging, team sports, fast dancing or jump-rope. Moderate PA was defined as "lower intensity activities" such as walking, biking to school and recreational swimming. The responses were then used to construct two PA outcomes. The first was a continuous outcome: the average time spent in MVPA (minutes/day). This outcome was calculated as the total of combined vigorous and moderate PA time divided by 7 days. The second was a binary outcome: whether or not the participants complied with the Canadian PA guideline of at least 60 minutes of MVPA 
per day. These measures have demonstrated a satisfactory 1-week test-retest reliability (intraclass correlation [ICC] $=0.75$ ). The measures were also significantly correlated with accelerometer-measured behaviours $(r=0.31$, ICC $=0.25)$. While correlations between self-report and objective measures were low to modest, the results are comparable to most other studies using accelerometers to validate selfreport PA. ${ }^{33}$

\section{Predictor variables}

Items for measuring the predictor variables, including parental encouragement, instrumental support and number of active peers, are adopted from the survey used in the School Health Action, Planning and Evaluation System (SHAPES) Physical Activity Module. ${ }^{34}$ As described elsewhere, these items are also consistent with the measures used in existing Canadian youth surveillance tools. ${ }^{32}$

\section{Parental encouragement and instrumental support}

Parental encouragement was measured annually over the three-year period using a single item: "How much do your parents, stepparents, or guardians encourage you to be physically active?" Responses were recorded on a 5-point Likert scale ranging from "strongly encourage" to "strongly discourage." This item was reverse coded with 1 = strongly discourage to $5=$ strongly encourage. Parental instrumental support was also measured annually using the following item from the Cq: "How much do your parents, stepparents, or guardians support you in being physically active (e.g. driving you to team games, buying you sporting equipment?)." Answers were recorded on a 4-point Likert scale ranging from "very unsupportive" to "very supportive."

\section{Number of active peers}

The number of active peers was measured annually using the following question from the Cq: "Your closest friends are the friends you like to spend the most time with. How many of your closest friends are physically active?" The response was recorded on a 6-point Likert scale ranging from 0 to $5+$.

\section{Covariates}

Other potential covariates that have been found to be associated with changes in adolescent PA, including age, grade attended, sex and race/ethnicity during each assessment, were self-reported using the Cq. ${ }^{35}$

\section{Statistical analysis}

We calculated descriptive statistics for all the study variables, and compared the differences between included and excluded participants. We used pairwise $t$ tests to examine temporal variations in parental and peer influences. We conducted preliminary analyses to explore the bivariate relationship between each potential predictor and each of the two dependent variables, and significant variables $(p<.05)$ were retained for the longitudinal analyses.

We used a linear-mixed model to examine the longitudinal effects of parental and peer influences on MVPA trajectory. We used a generalized estimation equation (GEE) to estimate the longitudinal effects of parental and peer influences on changes in the probability of complying with Canadian PA guidelines over time. In these models, we used age as the time variable to represent the change in the PA outcomes. Parental encouragement, parental instrumental support and number of active peers were used as time-varying predictors, and sex, ethnicity and grade attended as time-invariant covariates. The parental and peer influence variables were mutually adjusted in the models (e.g. the parental encouragement model controlled parental instrumental support and number of active peers as covariates).

With an accelerated longitudinal design, the effect of the time-varying covariates on the outcome embodies an aggregation of both between-person (cross-sectional effects) and within-person effects (longitudinal effects). ${ }^{36,37}$ Therefore, we needed to disaggregate these effects to avoid confounding longitudinal effects with crosssectional information.

Following the approach suggested by $\mathrm{Yu}$ and colleagues, ${ }^{37}$ we conducted meancentred transformations of the time-varying covariates, including age, parental encouragement, parental instrumental support and number of active peers. For each individual, we first calculated a personmean of the time-varying variable by averaging the values across the three time points. Then, we calculated a personmean-centred variable by subtracting the person-mean from the individual's time- specific observed values. Using age as an example, if an individual was measured three times at age 15, 16 and 17, then their person-mean of age would be 16 and the person-mean-centred age for the three time points would be coded as $-1,0$ and 1 , respectively. Both the person-mean and person-mean-centred terms were included in the models. Since we are interested in the longitudinal effects of the time-varying variables, the effects of the person-meancentred covariates in the specified model are of interest. These models also tested several interaction terms, including sex and age, and sex and the parental and peer influence variable, but none of these attained statistical significance. Therefore, the analyses were not stratified by sex.

We conducted the analyses using the statistical software package SAS version 9.4 (SAS Institute Inc., Cary, NC, USA). To meet the normality assumption, we performed a square-root transformation on the average MVPA minutes per day. We used the PROC MIXED procedure for the linear mixed-effects models and PROC GENMOD for the GEE model. The correlation structure of the GEE model was determined based on quasi-likelihood under the independence model criterion (QIC) an extension of Akaike's Information Criterion. Residual and studentized residual plots were used to confirm model assumptions and fit. Statistical significance was set at $p<.05$ for all analyses.

\section{Results}

Table 1 presents descriptive statistics. The final longitudinal sample comprised 22909 participants, of which 4449 participants had complete Cq data for all three years; 5353 for only Year 1 and Year 2; and 13107 for only Year 2 and Year 3. The included sample is significantly different from the excluded sample in terms of age, sex, race/ethnicity, scores in parental and peer influence variables and MVPA, but there is no difference in the proportion meeting PA guidelines. Findings from pairwise $t$ tests indicated that parental encouragement, instrumental support and number of active peers were significantly lower in Year 2 than in Year 1, and lower in Year 3 than in Year 2 (Table 2).

\section{Changes in parental and peer influences and changes in MVPA}

Table 3 presents results from the linearmixed models. Coefficients from the 
TABLE 1

Differences in the characteristics of the included and excluded participants, COMPASS study, 2012/13, 2013/14 and 2014/15

\begin{tabular}{|c|c|c|c|}
\hline Variable & $\begin{array}{l}\text { Included participants } \\
\qquad(\mathrm{n}=22909)\end{array}$ & $\begin{array}{l}\text { Excluded participants } \\
\qquad(\mathrm{n}=3172)\end{array}$ & $p$-value \\
\hline Age (Y2, mean and SD) & $15.42 \pm 1.12$ & $15.34 \pm 1.19$ & $<.001$ \\
\hline Sex, n (\%) & & & $<.001$ \\
\hline Girls & $12328 \quad(53.81)$ & 1380 & \\
\hline Boys & 10581 & $1790 \quad(56.47)$ & \\
\hline Race/ethnicity, n (\%) & & & $<.001$ \\
\hline White & $19428 \quad(84.81)$ & $1924 \quad(60.66)$ & \\
\hline Black & $736 \quad(3.21)$ & $270 \quad(8.51)$ & \\
\hline Asian & 1245 & $186 \quad(5.86)$ & \\
\hline Aboriginal & $500 \quad(2.18)$ & $195 \quad(6.15)$ & \\
\hline L. Am./Hisp. & 385 (1.68) & $117 \quad(3.69)$ & \\
\hline Others/mixed/missing & 615 (2.68) & $480 \quad(15.13)$ & \\
\hline Grade (Y2), n (\%) & & & $<.001$ \\
\hline 9 & 6405 (27.96) & 1100 & \\
\hline 10 & $7190 \quad(31.39)$ & $903 \quad(28.47)$ & \\
\hline 11 & 6240 (27.24) & $695 \quad(21.91)$ & \\
\hline 12 & 3074 (13.42) & $474 \quad(14.94)$ & \\
\hline $\begin{array}{l}\text { Parental encouragement } \\
\text { (Y2, mean and SD) }\end{array}$ & $4.03 \pm 0.75$ & $3.91 \pm 0.817$ & $<.001$ \\
\hline $\begin{array}{l}\text { Parental instrumental } \\
\text { support (Y2, mean and SD) }\end{array}$ & $3.46 \pm 0.63$ & $3.33 \pm 0.68$ & $<.001$ \\
\hline $\begin{array}{l}\text { Number of active peers } \\
\text { (Y2, mean and SD) }\end{array}$ & $3.36 \pm 1.64$ & $3.26 \pm 1.70$ & .002 \\
\hline $\begin{array}{l}\text { MVPA }(\min / \mathrm{d})(\mathrm{Y} 2 \\
\text { mean and } \mathrm{SD})\end{array}$ & $119.3 \pm 82.33$ & $123.6 \pm 96.10$ & .028 \\
\hline \multicolumn{3}{|c|}{ Compliance with PA guideline (Y2), n (\%) } & .356 \\
\hline Yes & 10875 & $1284 \quad(48.42)$ & \\
\hline No & $12034 \quad(52.53)$ & $1368 \quad(51.58)$ & \\
\hline
\end{tabular}

Abbreviations: L. Am./Hisp., Latin American/Hispanic; min/d, minutes per day; MVPA, moderate-to-vigorous physical activity; PA, physical activity; SD, standard deviation; Y2, Year 2.

Note: $p$-value $<.05$ indicates the included and excluded participants were significantly different in a given variable.

TABLE 2

Pairwise comparisons in parental encouragement, parental instrumental support and number of active peers scores across the COMPASS study, years 2012/13, 2013/14 and 2014/15

\begin{tabular}{lcc}
\multicolumn{1}{c}{ Variables } & $\begin{array}{c}\text { Year 2 }- \text { Year } 1 \\
(\mathbf{n}=\mathbf{9 ~ 8 0 2 )} \\
\text { Difference }(95 \% \mathrm{Cl})\end{array}$ & $\begin{array}{c}\text { Year 3 }- \text { Year } 2 \\
(\mathbf{n}=17556) \\
\text { Difference }(95 \% \mathrm{Cl})\end{array}$ \\
\hline Parental encouragement & $-0.0535(-0.0677$ to -0.0393$)$ & $-0.0395(-0.0499$ to -0.0291$)$ \\
\hline Parental instrumental support & $-0.0275(-0.0400$ to -0.0151$)$ & $-0.0235(-0.0326$ to -0.0144$)$ \\
\hline Number of active peers & $-0.2427(-0.2747$ to -0.2107$)$ & $-0.2395(-0.2630$ to -0.2160$)$ \\
\hline
\end{tabular}

Abbreviation: $\mathrm{Cl}$, confidence interval. cross-sectional parameters (i.e. "average" in Table 3) show that adolescent boys were more likely to engage in MVPA than girls. MVPA was higher among White adolescents than Black, Asian and Latin American/Hispanic youth as well as adolescents in the "Others" race/ethnicity category, but higher among Aboriginal youth than White youth. Attending a lower grade, having higher average scores in parental encouragement and instrumental support and reporting a higher number of active peers were all associated with higher levels of MVPA.

Coefficients from the longitudinal parameters (i.e. "difference" in Table 3 ) indicate that, after controlling for sex, ethnicity, grade, and parental and peer influences, there was a linear annual decline in adolescents' MVPA over the three-year period $(\beta=-0.28$, 95\% CI: $0.16-0.29, p<.001)$. Changes in parental and peer influence variables were positively associated with changes in MVPA trajectory. For a oneunit increase in the score of parental encouragement, parental instrumental support and number of active peers, average MVPA significantly increased by 0.22 units, 0.23 units and 0.16 units, respectively.

Changes in parental and peer influences and changes in probability of meeting $P A$ guidelines

Results from the GEE models are presented in Table 4. Coefficients (i.e. "average” in Table 4) from the cross-sectional parameters show that the odds of complying with the Canadian PA guidelines were higher among adolescent boys than girls. Similar to findings for MVPA, the odds of meeting the guidelines were higher among White youth than Black, Asian and Latin American/Hispanic youth and those in the "Others" race/ethnicity category, but higher among Aboriginal youth than White youth. Attending a lower grade, having higher average scores in parental encouragement and parental instrumental support and reporting a higher number of active peers were associated with higher odds of meeting the guidelines.

Coefficients from the longitudinal parameters (i.e. "difference" in Table 4) show that the odds of an adolescent complying with the Canadian PA guidelines decreased by $5 \%$ over the three-year period $(p=.009)$, after controlling for sex, race/ethnicity, grade, and parental and peer influences. 
TABLE 3

Longitudinal effects of parental and peer influences

on moderate-to-vigorous physical activity (MVPA),

COMPASS study, years 2012/13, 2013/14 and 2014/15

\begin{tabular}{|c|c|c|c|c|}
\hline Characteristic & Category & Coefficient ( $\beta$ ) & $95 \% \mathrm{Cl}$ & $p$-value \\
\hline Intercept & & 3.834 & (3.054 to 4.615$)$ & $<.001$ \\
\hline \multicolumn{5}{|l|}{ Time-invariant covariates } \\
\hline \multirow[t]{2}{*}{ Sex } & Girls & Ref & - & - \\
\hline & Boys & 0.848 & (0.767 to & $<.001$ \\
\hline \multirow[t]{6}{*}{ Ethnicity } & White & Ref & - & - \\
\hline & Black & -0.005 & $(-0.226$ to 0.216$)$ & .964 \\
\hline & Asian & -0.994 & $(-1.172$ to -0.816$)$ & $<.001$ \\
\hline & Aboriginal & 0.277 & (0.005 to & .046 \\
\hline & L. Am./Hisp. & -0.132 & $(-0.426$ to 0.163$)$ & .382 \\
\hline & Others & -0.237 & $(-0.456$ to -0.018$)$ & .034 \\
\hline Grade & Average & -0.280 & $(-0.390$ to -0.171$)$ & $<.001$ \\
\hline \multicolumn{5}{|l|}{ Time-varying predictors } \\
\hline \multirow[t]{2}{*}{ Age } & Average & 0.164 & (0.068 to & .001 \\
\hline & Difference & -0.276 & $(-0.316$ to -0.236$)$ & $<.001$ \\
\hline \multirow[t]{2}{*}{ Parental encouragement } & Average & 0.486 & (0.412 to & $<.001$ \\
\hline & Difference & 0.224 & (0.159 to & $<.001$ \\
\hline \multirow[t]{2}{*}{$\begin{array}{l}\text { Parental instrumental } \\
\text { support }\end{array}$} & Average & 0.702 & (0.611 to & $<.001$ \\
\hline & Difference & 0.225 & (0.151 to & $<.001$ \\
\hline \multirow[t]{2}{*}{ Number of active peers } & Average & 0.627 & (0.597 to & $<.001$ \\
\hline & Difference & 0.156 & (0.127 to & $<.001$ \\
\hline
\end{tabular}

Abbreviations: Cl, confidence interval; L. Am./Hisp., Latin American/Hispanic; Ref, reference group.

Notes: MVPA was square-root transformed. "Average" is the mean value of the time-varying variable of an individual across the three time points. "Difference" is the difference between an individual's mean value of the time-varying variable and the observed value at a specific time point.

Positive changes in the scores of the parental and peer influence variables increased the odds of complying with the PA guidelines. For a one-unit increase in the score of parental encouragement, parental instrumental support, and number of active peers, adjusted odds of an adolescent complying with the PA guidelines increased by $9 \%, 4 \%$ and $6 \%$, respectively.

\section{Discussion}

Our findings showed that parental encouragement, parental instrumental support and number of active peers significantly declined within individuals over the threeyear period. This is important because each unit change in these variables was independently and positively associated with changes in adolescent PA levels and the odds of meeting Canadian PA guidelines for children and youth. Adolescents were more likely to engage in MVPA and meet the guideline if they reported more parental encouragement, parental instrumental support and active peers. This new structs are potentially modifiable. The findings can also inform the grading of peer- and family-related indicators in future iterations of ParticipACTION's Report Card on Physical Activity for Children and Youth.

Parental encouragement and parental instrumental support decreased significantly across Grades 9 to 12 . These findings are consistent with previous studies focussing on adolescent girls. ${ }^{22,24}$ Davison and Jago showed that girls' perceived parental insight is promising as all of those con- instrumental support significantly decreased across ages 9 to $15 .^{22}$ Dowda et al. found that girls' perceived family support significantly declined from Grade 8 to Grade $12 .{ }^{24}$ Our findings contribute to the literature by demonstrating longitudinal effects of parental encouragement and instrumental support on PA in both adolescent boys and girls.

The finding that increments in parental encouragement and instrumental support were significantly associated with increased adolescent PA over time is partially consistent with previous studies. ${ }^{22,24}$ Dowda et al. found that an elevated self-reported PA as measured by total Metabolic Equivalent (MET) scores was predicted by an increase in family support from Grade 8 to Grade 12. ${ }^{24}$ Davison and Jago demonstrated that adolescent girls had higher odds of meeting PA guidelines across ages 9 to 15 years if they perceived higher levels of parental modelling, but not parental instrumental support. ${ }^{22}$ The inconsistent findings could be related to the difference in conceptualization of parental influences across studies (i.e. Dowda et al. used a composite variable, while Davison and Jago quantified specific aspects of parental influences). While more longitudinal studies are needed to disentangle the effects of different kinds of parental influences on PA among adolescents, continued efforts are also required to standardize definitions and measures in the field to allow meaningful comparisons across studies.

For peer influences, other researchers have focussed on temporal variations in children's social networks and found that the number of outgoing and incoming (general) friendships did not predict changes in PA. ${ }^{16}$ To the authors' knowledge, no study has specifically examined temporal variations in the number of active peers and their effect on changes in PA. Our study is the first to show that the number of active peers significantly decreased across adolescence. A unit increase in the number of physically active friends significantly increased PA levels and the odds of meeting PA guidelines. The mechanisms explaining these positive relationships remain speculative. It is unclear whether having more physically active peers may have influenced adolescents' PA by increasing their motivation to be physically active, by promoting PA norms among peers or by providing companions for PA, or whether other mechanisms were involved. ${ }^{29,38}$ Future studies should 
TABLE 4

Longitudinal effects of changes in parental and peer influences on changes in compliance with Canadian physical activity guidelines, COMPASS study, years 2012/13, 2013/14 and 2014/15

\begin{tabular}{|c|c|c|c|c|}
\hline Variables & Category & $\begin{array}{l}\text { Odds ratio } \\
\text { (OR) }\end{array}$ & $95 \% \mathrm{Cl}$ & $p$-value \\
\hline Intercept & & 0.154 & $(0.097-0.244)$ & $<.001$ \\
\hline \multicolumn{5}{|l|}{ Time-invariant covariates } \\
\hline \multirow[t]{2}{*}{ Sex } & Girls & Ref & - & - \\
\hline & Boys & 1.676 & $(1.596-1.761)$ & $<.001$ \\
\hline \multirow[t]{6}{*}{ Ethnicity } & White & Ref & - & - \\
\hline & Black & 0.783 & $(0.692-0.885)$ & $<.001$ \\
\hline & Asian & 0.593 & $(0.518-0.680)$ & $<.001$ \\
\hline & Aboriginal & 1.143 & $(1.006-1.299)$ & .041 \\
\hline & L. Am./Hisp. & 0.737 & $(0.642-0.847)$ & $<.001$ \\
\hline & Others & 0.845 & $(0.746-0.958)$ & .008 \\
\hline Grade & Average & 1.062 & (1.009-1.118) & .022 \\
\hline \multicolumn{5}{|l|}{ Time-varying predictors } \\
\hline \multirow[t]{2}{*}{ Age } & Average & 0.904 & $(0.851-0.961)$ & .001 \\
\hline & Difference & 0.948 & $(0.911-0.987)$ & .009 \\
\hline \multirow[t]{2}{*}{ Parental encouragement } & Average & 1.190 & $(1.145-1.237)$ & $<.001$ \\
\hline & Difference & 1.088 & $(1.046-1.133)$ & $<.001$ \\
\hline \multirow[t]{2}{*}{ Parental instrumental support } & Average & 1.099 & $(1.039-1.162)$ & .001 \\
\hline & Difference & 1.039 & $(0.991-1.090)$ & .113 \\
\hline \multirow[t]{2}{*}{ Number of active peers } & Average & 1.227 & (1.207-1.248) & $<.001$ \\
\hline & Difference & 1.058 & (1.037-1.079) & $<.001$ \\
\hline
\end{tabular}

Abbreviations: $\mathrm{Cl}$, confidence interval; L. Am./Hisp., Latin American/Hispanic; Ref, reference group.

Notes: "Average" is the mean value of the time-varying variable across the three time points. "Difference" is the difference between the mean value and the reported value.

also examine factors that influence adolescents to form or dissolve friendships with physically active peers. Also, specific characteristics of the PA friendship network should be explored, such as composition and type of activities in which active peers participate, both of which are associated with changes in adolescent PA over time. ${ }^{39}$

Declines in PA during adolescence are commonly reported. ${ }^{40,41}$ Our findings suggest that interventions to attenuate these declines should include encouraging parents to provide more encouragement and increase instrumental support for PA to their children, and should consider the role peers may play. While best practices for family-based PA interventions for youth remain to be identified, ${ }^{42,43}$ limited evidence suggests that public health professionals could increase parental support for PA using parent-child targeted training, family counselling and preventive messages during family visits. ${ }^{42}$ Social marketing campaigns (such as the ParticipACTION “Think Again” campaign) ${ }^{44}$ may also have a role to play in educating parents about their important role in providing support.

Likewise, there is little available evidence on peer-based PA interventions. To our knowledge, there are no interventions aimed at increasing the number of physically active friends of an adolescent. One age-appropriate channel for meeting more physically active friends is social media (e.g. Facebook). ${ }^{45}$ Another possible intervention is to increase the number of physically active friends within an existing friendship network. This can be done by changing peer PA norms using social marketing campaigns, such as the VERB campaign, ${ }^{46}$ to communicate that physical activity is something that friends do together. Encouraging adolescents to participate in group-based physical activities (organized or recreational) could also help them increase the number of their active peers and/or friends. ${ }^{47}$

\section{Strengths and limitations}

This study has considerable strengths. The longitudinal design allowed us to determine temporal sequences and patterns of change in these parental and peer influences, providing important insight informing the design and timing of future interventions. Using the multilevel mixedeffect models allowed us to incorporate individual and school-level variations in the analyses, which increased the accuracy of parameter estimations. The large sample size (children were recruited from nearly 90 schools) increased the precision of population parameter estimations.

This study is limited in that all measures were self-reported and PA assessment is particularly prone to reporting error. Also, given the need for developing a comprehensive yet brief survey for the COMPASS platform, there were only two parental influences (parental encouragement and parental instrumental support) and one measure of active peers included. Although these influences have been found to be more strongly associated with adolescent PA than parental role modelling, positive communication and co-participation, ${ }^{25,27,28,48}$ there are likely other important dimensions we did not consider.

In our study, we asked participants to selfreport the number of closest friends that are physically active. This approach provides only an indirect measure of the PA levels of friends. We recommend that future studies use a more comprehensive social network measure (such as that used by Sawka et $\left.a{ }^{49}\right)$. For example, participants could be provided with a class list and asked to identify their active peers. The self-reported activity levels of those identified could then be linked.

In addition, although there are other covariates that might confound the associations of interest, such as child's selfefficacy, self-esteem, perceived competence and subjective values, ${ }^{25}$ we did not adjust for those. Finally, characteristics of students included in the analytical sample were different from the excluded sample, 
which suggests the possibility of attrition biases. Nonetheless, attrition is an inherent limitation in prospective observational studies.

\section{Conclusion}

This study found significant declining trends in parental encouragement, instrumental supports and number of active peers from Grades 9 to 12, which was associated with reductions in PA levels and decreased odds of meeting PA guidelines. Promoting parental encouragement and instrumental support and facilitating the formation and maintenance of a physically active friendship network may be important for attenuating the decline in PA during adolescence.

\section{Acknowledgements}

The COMPASS study was supported by a bridge grant from the Canadian Institutes of Health Research (CIHR) Institute of Nutrition, Metabolism and Diabetes (INMD) through the "Obesity-Interventions to Prevent or Treat” priority funding awards (OOP-110788; grant awarded to S. T. Leatherdale) and an operating grant from the CIHR Institute of Population and Public Health (IPPH) (MOP-114875; grant awarded to S. T. Leatherdale). Drs. Faulkner and Leatherdale are Chairs in Applied Public Health Research funded by the Public Health Agency of Canada in partnership with CIHR.

\section{References}

1. Janssen I, LeBlanc A. Systematic review of the health benefits of physical activity and fitness in school-aged children and youth. Int $\mathrm{J}$ Behav Nutr Phys Act. 2010;7(1):40.

2. Hallal P, Victora C, Azevedo M, Wells JK. Adolescent physical activity and health. Sports Med. 2006;36(12): 1019-30.

3. United States Department of Health and Human Services. Youth risk behavior surveillance-United States, 2013. Morb Mortal Wkly Rep. 2014; 63(4).

4. Statistics Canada. Canadian Community Health Measures Survey-Cycle 3, 2012 to 2013. Ottawa (ON): Statistics Canada; 2014.
5. Tremblay MS, Gray CE, Akinroye K, Harrington DM, Katzmarzyk PT, Lambert EV, et al. Physical activity of children: a global matrix of grades comparing 15 countries. J Phys Act Health. 2014;11 Suppl 1:S113-25.

6. Azevedo MR, Araújo CL, Cozzensa da Silva M, Hallal PC. Tracking of physical activity from adolescence to adulthood: a population-based study. Revista de Saúde Pública. 2007;41: 69-75.

7. Sallis JF, Owen N, Fotheringham MJ. Behavioral epidemiology: a systematic framework to classify phases of research on health promotion and disease prevention. Ann Behav Med. 2000;22(4):294-8.

8. Spence JC, Lee RE. Toward a comprehensive model of physical activity. Psychol Sport Exerc. 2003;4(1):7-24.

9. Craggs $\mathrm{C}$, Corder $\mathrm{K}$, van Sluijs EMF, Griffin SJ. Determinants of change in physical activity in children and adolescents: a systematic review. Am J Prev Med. 2011;40(6):645-658.

10. Bandura A. Social foundations of thought and action: a social cognitive theory. Englewood Cliffs (NJ): Prentice Hall; 1986.

11. Trost SG, Loprinzi PD. Parental influences on physical activity behavior in children and adolescents: a brief review. Am J Lifestyle Med. 2011;5(2):171-81.

12. Maturo CC, Cunningham SA. Influence of friends on children's physical activity: a review. Am J Public Health. 2013;103(7):e23-38.

13. Bergh IH, Bjelland M, Grydeland M, et al. Mid-way and post-intervention effects on potential determinants of physical activity and sedentary behavior, results of the HEIA study - a multi-component school-based randomized trial. Int J Behav Nutr Phys Act. 2012;9:63.

14. Bergh IH, van Stralen MM, Grydeland $M$, et al. Exploring mediators of accelerometer assessed physical activity in young adolescents in the Health In Adolescents Study - a group randomized controlled trial. BMC Public Health. 2012;12:814.
15. Corder K, Craggs C, Jones A, Ekelund U, Griffin S, van Sluijs E. Predictors of change differ for moderate and vigorous intensity physical activity and for weekdays and weekends: a longitudinal analysis. Int J Behav Nutr Phys Act. 2013;10(1):69.

16. Gesell SB, Tesdahl E, Ruchman E. The distribution of physical activity in an after-school friendship network. Pediatrics. 2012;129(6):1064-1071.

17. Hearst M, Patnode C, Sirard J, Farbakhsh K, Lytle L. Multilevel predictors of adolescent physical activity: a longitudinal analysis. Int J Behav Nutr Phys Act. 2012;9(1):8.

18. Kirby J, Levin KA, Inchley J. Parental and peer influences on physical activity among Scottish adolescents: a longitudinal study. J Phys Act Health. 2011;8(6):785-793.

19. Ornelas IJ, Perreira KM, Ayala GX. Parental influences on adolescent physical activity: a longitudinal study. Int J Behav Nutr Phys Act. 2007;4:3.

20. van Stralen MM, de Meij J, Te Velde SJ, et al. Mediators of the effect of the JUMP-in intervention on physical activity and sedentary behavior in Dutch primary schoolchildren from disadvantaged neighborhoods. Int $\mathrm{J}$ Behav Nutr Phys Act. 2012;9:131.

21. Bauer K, Nelson M, Boutelle K, Neumark-Sztainer D. Parental influences on adolescents' physical activity and sedentary behavior: longitudinal findings from Project EAT-II. Int $\mathrm{J}$ Behav Nutr Phys Act. 2008;5(1):12.

22. Davison KK, Jago R. Change in parent and peer support across ages 9 to 15 yr and adolescent girls' physical activity. Med Sci Sports Exerc. 2009;41(9): 1816-1825.

23. Morrissey JL, Janz KF, Letuchy EM, Francis SL, Levy SM. The effect of family and friend support on physical activity through adolescence: a longitudinal study. Int J Behav Nutr Phys Act. 2015;12(1):103.

24. Dowda M, Dishman RK, Pfeiffer KA, Pate RR. Family support for physical activity in girls from 8th to 12th grade in South Carolina. Prev Med. 2007; 44(2):153-159. 
25. Beets MW, Cardinal BJ, Alderman BL. Parental social support and the physical activity-related behaviors of youth: a review. Health Educ Behav. 2010; 37(5):621-644.

26. Dishman RK, Saunders RP, Motl RW, Dowda M, Pate RR. Self-efficacy moderates the relation between declines in physical activity and perceived social support in high school girls. J Pediatr Psychol. 2009;34(4): 441-451.

27. Beets MW, Vogel R, Forlaw L, Pitetti $\mathrm{KH}$, Cardinal BJ. Social support and youth physical activity: the role of provider and type. Am J Health Behav. 2006;30(3):278-289.

28. Edwardson CL, Gorely T. Parental influences on different types and intensities of physical activity in youth: a systematic review. Psychol Sport and Exerc. 2010;11(6):522-535.

29. Fitzgerald A, Fitzgerald N, Aherne C. Do peers matter? A review of peer and/or friends' influence on physical activity among American adolescents. J Adolesc. 2012;35(4):941-958.

30. ParticipACTION. The 2015 ParticipACTION report card on physical activity for children and youth: the biggest risk is keeping kids indoors. Toronto (ON): ParticipACTION; 2015.

31. Tremblay MS, Barnes JD, Cowie Bonne J. Impact of the Active Healthy Kids Canada Report Card: a 10-year analysis. J Phys Act Health. 2014;11 Suppl 1:S3-s20.

32. Leatherdale ST, Brown KS, Carson V, et al. The COMPASS study: a longitudinal hierarchical research platform for evaluating natural experiments related to changes in school-level programs, policies and built environment resources. BMC Public Health. 2014; $14: 331$.

33. Leatherdale ST, Laxer R, Faulkner G. Reliability and validity of physical activity and sedentary behavior measures in the COMPASS study. Waterloo (ON): University of Waterloo; 2014.

34. Leatherdale ST, Manske S, Wong SL, Cameron R. Integrating research, policy, and practice in school-based physical activity prevention programming: the School Health Action, Planning, and Evaluation System (SHAPES) Physical Activity Module. Health Promot Pract. 2009;10(2):254-261.
35. Sterdt E, Liersch S, Walter U. Correlates of physical activity of children and adolescents: a systematic review of reviews. Health Educ J. 2014; 73(1):72-89

36. Curran PJ, Bauer DJ. The disaggregation of within-person and betweenperson effects in longitudinal models of change. Ann Rev Psychol. 2011;62: 583-619.

37. Yu O, Sheppard L, Lumley T, Koenig JQ, Shapiro GG. Effects of ambient air pollution on symptoms of asthma in Seattle-area children enrolled in the CAMP study. Environ Health Perspect. 2000;108(12):1209-1214.

38. Salvy S-J, de la Haye K, Bowker JC, Hermans RCJ. Influence of peers and friends on children's and adolescents' eating and activity behaviors. Physiol behav. 2012;106(3):369-378

39. Marks J, de la Haye K, Barnett LM, Allender S. Friendship network characteristics are associated with physical activity and sedentary behavior in early adolescence. PloS One. 2015; 10(12):e0145344.

40. Basterfield L, Adamson AJ, Frary JK, et al. Longitudinal study of physical activity and sedentary behavior in children. Pediatrics. 2011;127(1):e24-30.

41. Dumith SC, Gigante DP, Domingues MR, Kohl HW. Physical activity change during adolescence: a systematic review and a pooled analysis. Int J Epidemiol. 2011;40(3):685-698.

42. O’Connor TM, Jago R, Baranowski T. Engaging parents to increase youth physical activity: a systematic review. Am J Prev Med. 2009;37(2):141-149.

43. Van Lippevelde W, Verloigne $M$, De Bourdeaudhuij I, et al. Does parental involvement make a difference in school-based nutrition and physical activity interventions? A systematic review of randomized controlled trials. Int J Public Health. 2012;57(4): 673-678

44. Gainforth HL, Jarvis JW, Berry TR, et al. Evaluating the ParticipACTION "Think Again" Campaign. Health Educ Behav. 2016;43(4):434-41.

45. Cavallo DN, Tate DF, Ries AV, Brown JD, DeVellis RF, Ammerman AS. A social media-based physical activity intervention: a randomized controlled trial. Am J Prev Med. 2012;43(5): 527-532.
46. Huhman ME, Potter LD, Duke JC, Judkins DR, Heitzler CD, Wong FL. Evaluation of a national physical activity intervention for children: VERB campaign, 2002-2004. Am J Prev Med. 2007;32(1):38-43.

47. Ginis KAM, Nigg CR, Smith AL. Peerdelivered physical activity interventions: an overlooked opportunity for physical activity promotion. Transl Behav Med. 2013;3(4):434-443.

48. Yao C, Rhodes R. Parental correlates in child and adolescent physical activity: a meta-analysis. Int $\mathrm{J}$ Behav Nutr Phys Act. 2015;12(1):10.

49. Sawka KJ, McCormack GR, NettelAguirre A, Blackstaffe A, Perry R, Hawe P. Associations between aspects of friendship networks, physical activity, and sedentary behaviour among adolescents. J Obes. 2014; 2014:632689. doi: 10.1155/2014/632689. 